Article

\title{
Transforming Waste Clamshell into Highly Selective Nanostructured Catalysts for Solvent Free Liquid Phase Oxidation of Benzyl Alcohol
}

\author{
Nafiseh Sadat Saffari ${ }^{1}$, Behzad Aghabarari ${ }^{1, *(D)}$, Masoumeh Javaheri ${ }^{2}$, Ali Khanlarkhani ${ }^{1}$ (D) \\ and Maria Victoria Martinez-Huerta ${ }^{3}$
}

check for updates

Citation: Saffari, N.S.; Aghabarari, B.; Javaheri, M.; Khanlarkhani, A.;

Martinez-Huerta, M.V. Transforming Waste Clamshell into Highly Selective Nanostructured Catalysts for Solvent Free Liquid Phase Oxidation of Benzyl Alcohol. Catalysts 2022, 12, 155. https:// doi.org/10.3390/catal12020155

Academic Editor: Luísa

Margarida Martins

Received: 26 December 2021

Accepted: 23 January 2022

Published: 27 January 2022

Publisher's Note: MDPI stays neutral with regard to jurisdictional claims in published maps and institutional affiliations.

Copyright: (C) 2022 by the authors. Licensee MDPI, Basel, Switzerland. This article is an open access article distributed under the terms and conditions of the Creative Commons Attribution (CC BY) license (https:// creativecommons.org/licenses/by/ $4.0 /)$
1 Nanotechnology and Advanced Materials Department, Materials and Energy Research Center, Karaj 31787-316, Iran; nafise.saffari@yahoo.com (N.S.S.); a.khanlarkhani@merc.ac.ir (A.K.)

2 Department of Ceramic, Materials and Energy Research Center, Karaj 31787-316, Iran; m.javaheri@merc.ac.ir 3 Institute of Catalysts and Petroleochemistry, CSIC, Marie Curie 2, 28049 Madrid, Spain; mmartinez@icp.csic.es

* Correspondence: b.aghabarari@merc.ac.ir

Abstract: High yield production of benzaldehyde in the solvent-free oxidation of benzyl alcohol by using green catalysts is highly desirable. In this work, calcium hydroxide derived from waste clamshell was used as low-cost and environmentally friendly catalyst support (CaSUP) for Pd and V nanoparticles. The physicochemical properties of the catalysts were analyzed using X-ray diffraction spectroscopy (XRD), Fourier transform infrared spectroscopy (FTIR), Brunauer-Emmett-Teller (BET) technique, scanning electron microscopy (SEM) and transmission electron microscopy (TEM). The catalytic oxidation of benzyl alcohol to benzaldehyde was studied in a liquid phase reaction by using $\mathrm{H}_{2} \mathrm{O}_{2}$ as an oxidizing agent. The effects of catalyst loading, the molar ratio of hydrogen peroxide to benzyl alcohol, temperature and reaction duration were investigated. In the optimized conditions, Pd nanoparticles supported on clamshell-derived supports displayed excellent catalytic conversion $(88 \%)$ and selectivity to benzaldehyde (89\%). Furthermore, the catalyst can be effectively reused without a significant loss in its activity and selectivity. The high yield and stability can be related to the structural and basic properties of the catalyst. These results provide important insights into the benzyl alcohol oxidation process for industrial applications.

Keywords: waste clamshell; calcium hydroxide; benzyl alcohol; palladium catalyst; benzaldehyde

\section{Introduction}

The selective oxidation reactions of alcohols into their related aldehyde and carbonyl compounds play a vital role in organic synthesis and fine chemical industrials [1]. Among them, the liquid phase selective oxidation of benzyl alcohol to benzaldehyde is an important reaction in the industry due to its demand as an intermediate in the production of cosmetics, fine chemicals, flavoring additives, pharmaceuticals and fragrances [2-5]. Traditionally, benzaldehyde is synthesized by the hydrolysis of benzal chloride, vapor/liquid phase oxidation of toluene and carbonylation of benzene. Nowadays, because of the low yield of benzaldehyde and the existence of hazardous by-products in the former processes, benzaldehyde is produced by the solvent-less oxidation of benzyl alcohol in the liquid/vapor phase [6,7]. In this process, inorganic oxidants such as hypochlorite [8], chromium (VI) [5], dichromate [9], manganese (IV) oxide [10] and potassium permanganate [11] play an important role in the quality of the reaction products. However, these oxidants suffer from several disadvantages (e.g., toxicity, high costs and the production of large amounts of waste) [12].

Considering environmental suitability, the production of benzaldehyde by solvent-free catalytic oxidation of benzyl alcohol with clean oxidants such as $\mathrm{H}_{2} \mathrm{O}_{2}$ or $\mathrm{O}_{2}$ is highly desirable $[2,3]$. A topic of new interest in this context is the design of environmentally friendly, 
recyclable, active and extremely selective heterogeneous nanocatalysts. In a comparative study, Pd nanoparticles appear as a new category of useful catalysts for the oxidation of benzyl alcohol with several benefits [13-17]. Unfortunately, high costs usually limit the large-scale use of noble metal-based catalysts such as Pd [16,17]. Therefore, more effort is needed to develop cost-efficient Pd catalysts for catalytic benzyl alcohol oxidation. In order to solve this problem, $\mathrm{Pd}$ nanoparticles can be dispersed on the surface of appropriate support, which can have a great effect not only on catalyst performance but also on catalyst production costs [18]. For example, Ying Li et al. fabricated palladium nanoparticles supported on iron-doped SBA-15 catalysts with an excellent catalytic performance toward solvent-free oxidation of benzyl alcohol using molecular oxygen under lower temperatures and atmospheric pressure and without additional bases [16]. Another option is to investigate heterogeneous noble metal-free catalysts for benzyl alcohol oxidation. Analía L. Cánepa et al. studied MCM-41 nanostructured materials modified with V, Fe or Co in the liquid phase oxidation of benzyl alcohol to benzaldehyde using $\mathrm{H}_{2} \mathrm{O}_{2}$ as oxidant. Results revealed that well-dispersed vanadium species in the framework (V-MCM-41) led to the best catalytic performance exhibiting a $31.7 \%$ yield at $7 \mathrm{~h}$ under optimized reaction conditions [19].

It is known that the incorporation of alkali metals into catalysts is beneficial for alkyl aromatic oxidation reactions because it improves (a) the hydrophilicity of the support surface, (b) the coordination of the metal ion and (c) the electron-donating potentiality [20]. However, few studies have been reported on the selective oxidation of benzyl alcohol to benzaldehyde using alkaline catalysts $[7,21]$. Vasant $R$. Choudhary et al. observed high activity for benzyl alcohol oxidation to benzaldehyde using MgO-supported nano-gold catalysts $\left(72.5 \%\right.$ yield) by tert-butyl hydroperoxide at $95^{\circ} \mathrm{C}$ [7]. Therefore, it is expected that calcium-based derivative materials with appropriate basicity could promote the oxidation of benzyl alcohol to benzaldehyde.

Calcium carbonate is mainly derived from natural sources such as limestone, calcite or marble [22-24]. However, extraction from these sources promotes environmental degradation, such as soil loss. In addition, $\mathrm{CaCO}_{3}$ is the main component of the shells of marine organisms such as snails, clams, pearls and eggshells [25]. Among them, one of the most widespread by-products in the maritime industry is the waste clamshell, which has the potential to be converted into high value-added products [26].

The aim of this study is to develop a low-cost and sustainable synthesis method to obtain active and stable catalysts for solvent-free liquid phase oxidation of benzyl alcohol. Instead of using expensive support with complex manufacturing processes, we have used waste clamshell as a precursor to prepare nanostructures containing calcium alkali metals for supported palladium and vanadium nanoparticles. To investigate their catalytic activity, numerous reaction parameters such as catalyst loading, the molar ratio of $\mathrm{H}_{2} \mathrm{O}_{2}$ to benzyl alcohol, temperature and reaction duration have been evaluated.

\section{Results and Discussion}

\subsection{Characterization}

\subsubsection{X-ray Diffraction (XRD)}

The powder X-ray diffraction analysis was carried out for the characterization of the catalyst's structure. Figure 1 displays the XRD pattern of uncalcined clamshell, calcined support (CaSUP) and Pd/CaSUP and V/CaSUP catalysts. The diffraction peaks of uncalcined support at $2 \theta=23.1^{\circ}, 29.3^{\circ}, 36.1^{\circ}, 39.4^{\circ}, 43.1^{\circ}, 47.5^{\circ}, 48.5^{\circ}$ are assigned to crystallite $\mathrm{CaCO}_{3}$ (JCPDS card: no.81-2027). Whereas for the calcined support, the diffraction peaks at $2 \theta=32.2^{\circ}, 37.4^{\circ}, 53.8^{\circ}, 64.2^{\circ}, 67.5^{\circ}$ correspond to $\mathrm{CaO}$ (JCPDS card: no. 77-2010), which confirms that the calcination process was successful and the $\mathrm{CaCO}_{3}$ phase was fully transformed into $\mathrm{CaO}$. It is interesting to mention that the XRD patterns of the Pd/CaSUP and V/CaSUP catalysts show characteristic diffraction peaks assigned to $\mathrm{Ca}(\mathrm{OH})_{2}$ (JCPDS card: no. 84-7273) and peaks of $\mathrm{CaCO}_{3}$ (JCPDS card: no. 81-2027). The presence of $\mathrm{Ca}(\mathrm{OH})_{2}$ indicates that the hydroxylation reaction occurred in between water 
and $\mathrm{CaO}$ phases during the synthesis of $\mathrm{Pd}$ and $\mathrm{V}$ catalysts. Furthermore, the formation of $\mathrm{CaCO}_{3}$ can be due to physisorbed $\mathrm{CO}_{2}$ on the surface of catalysts, which were exposed to ambient air in the thermal treatment $[27,28]$. Diffraction peaks corresponding to $\mathrm{Pd}$ and $\mathrm{V}$ species were not detected, probably due to their low particle sizes $(<5 \mathrm{~nm})$ or their being in amorphous states.

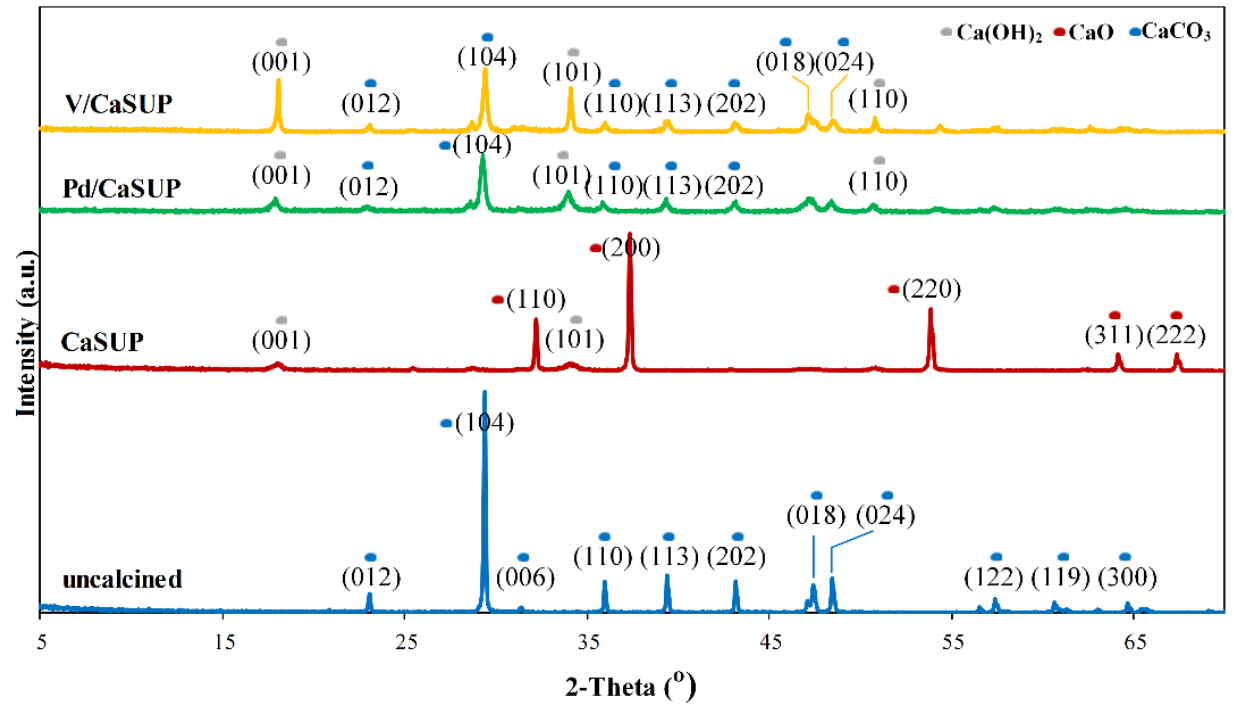

Figure 1. XRD spectra of uncalcined support: CaSUP, Pd/CaSUP and V/CaSUP.

\subsubsection{Fourier Transform Infrared Spectroscopy (FTIR)}

FTIR analysis was employed to characterize the chemical functional groups of uncalcined support, CaSUP, V/CaSUP and Pd/CaSUP (Figure 2). As expected, the uncalcined sample spectrum displays the characteristic FTIR bands of $\mathrm{CaCO}_{3}$ at $712 \mathrm{~cm}^{-1}\left(\mathrm{CO}_{3}{ }^{2-}\right.$ in-plane bend vibration mode), $872 \mathrm{~cm}^{-1}\left(\mathrm{CO}_{3}{ }^{2-}\right.$ out-of-plane bend vibration mode) and $1424 \mathrm{~cm}^{-1}$ (asymmetric stretching vibration mode of $\mathrm{CO}_{3}{ }^{2-}$ ) [29].

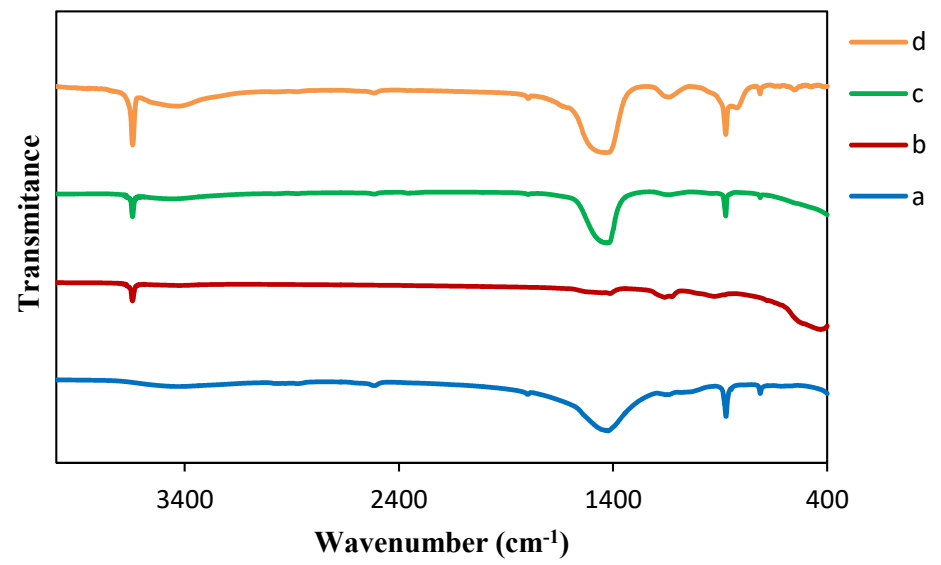

Figure 2. FT-IR spectra of (a) uncalcined support, (b) CaSUP, (c) Pd/CaSUP and (d) V/CaSUP.

The FTIR spectrum of the CaSUP shows four significant absorption bands. The broad bands at 1413,1158 and $928 \mathrm{~cm}^{-1}$ are ascribed to pure $\mathrm{CaO}$, while a strong band observed at $3644 \mathrm{~cm}^{-1}$ is assigned to the stretching vibration of $-\mathrm{OH}$ of the hydrated sample [22]. FTIR spectra of the V/CaSUP and Pd/CaSUP catalysts display - OH absorption bands at $3643 \mathrm{~cm}^{-1}$, which confirm the formation of $\mathrm{Ca}(\mathrm{OH})_{2}$ [27], and bands at 1429,874 and $713 \mathrm{~cm}^{-1}$ attributed to $\mathrm{CaCO}_{3}$. These results are in agreement with the XRD results and confirm the rehydration and carbonation of some $\mathrm{CaO}$ nanoparticles during the metalloading process. 


\subsubsection{Morphology Characterization and Chemical Composition}

The morphology of the CaSUP, Pd/CaSUP and V/CaSUP catalysts were studied by scanning electron microscopy (SEM) and transmission electron microscopy (TEM). Figure 3 shows the SEM images of the nanostructures. The morphology of the CaSUP shows an agglomerated structure of particles in the range of 40-90 nanometers. The Pd/CaSUP and $\mathrm{V} / \mathrm{CaSUP}$ catalysts show a similar particle size range to the CaSUP but with a lower level of agglomeration.
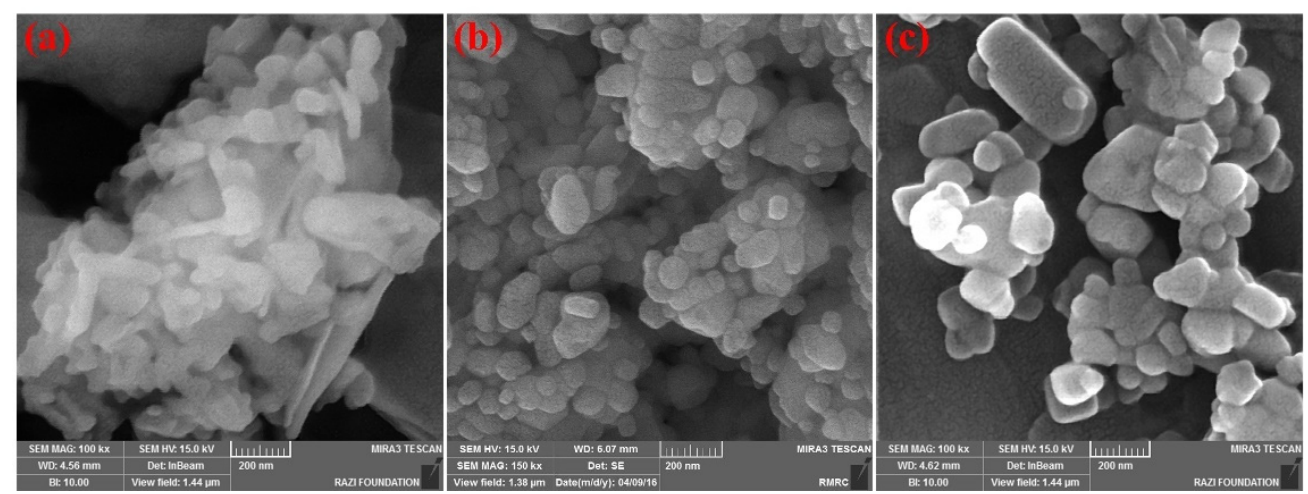

Figure 3. SEM images of (a) CaSUP, (b) V/CaSUP and (c) Pd/CaSUP.

Figure 4 shows TEM images of the CaSUP (Figure 4a) and Pd/CaSUP catalyst (Figure 4b-d). The TEM image of the CaSUP shows the irregular shape of particles with wide sizes ranging from 20 to $100 \mathrm{~nm}$. Despite the low Pd content in the Pd/CaSUP catalyst, it was possible to observe some nanoparticles with sizes below $5 \mathrm{~nm}$ in Figure 4c. The EDS results (Figure 4e) confirm the presence of the palladium element in the Pd/CaSUP catalyst.

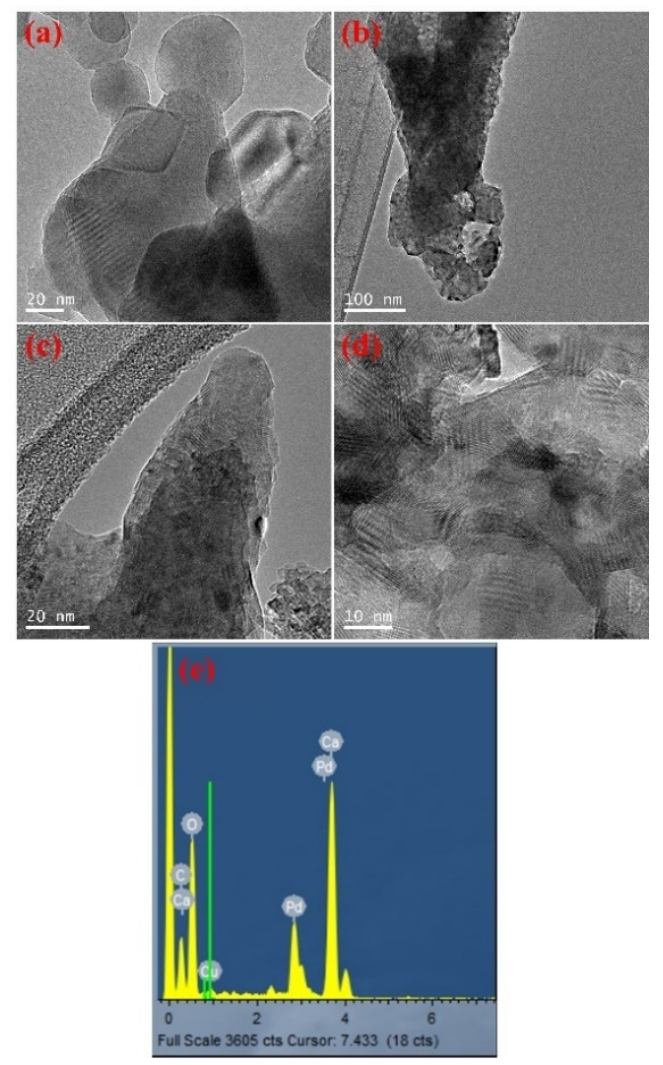

Figure 4. TEM images of (a) CaSUP, (b-d) Pd/CaSUP and (e) EDS of Pd/CaSUP. 
According to the ICP results, the Pd loading in the Pd/CaSUP catalyst was 0.85 wt.\% and the V loading was 0.91 wt. $\%$ in the V/CaSUP.

\subsubsection{BET Surface Area}

The nitrogen adsorption-desorption isotherms of the support (CaSUP), V/CaSUP and $\mathrm{Pd} / \mathrm{CaSUP}$ catalysts are displayed in Figure 5. The curves show a typical type III isotherm indicative of a nonporous or macroporous structure. BET surface area results of the CaSUP, $\mathrm{V} / \mathrm{CaSUP}$ and Pd/CaSUP catalysts are 2.4, 9.1 and $13.5 \mathrm{~m}^{2} \mathrm{~g}^{-1}$, respectively. The different crystalline structure of the CaSUP support before adding Pd and V nanoparticles $(\mathrm{CaO})$ and the support in the V/CaSUP and Pd/CaSUP catalysts $\left(\mathrm{Ca}\left(\mathrm{OH}_{2}\right)\right)$ detected by the XRD analysis can explain the differences observed in the specific surface areas of the catalysts.

a)

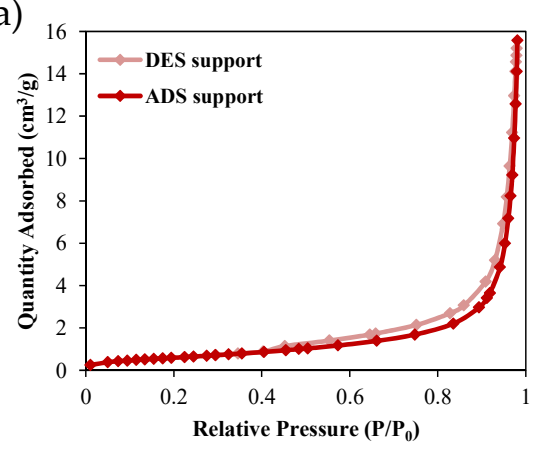

b)

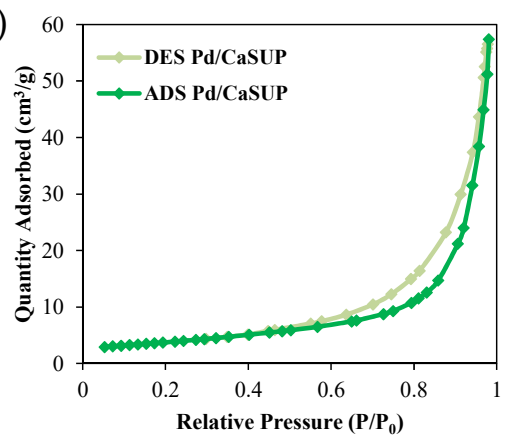

c)

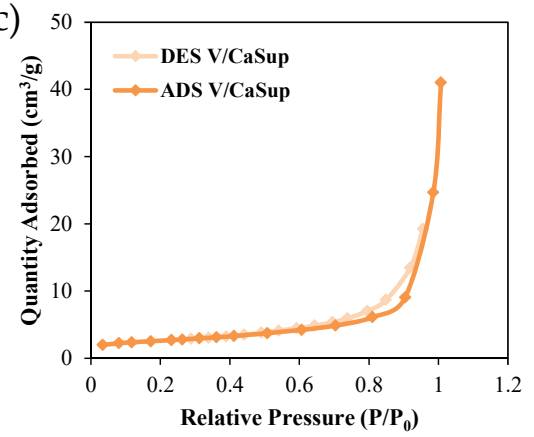

Figure 5. Adsorption-desorption isotherm of (a) support (CaSUP), (b) Pd/CaSUP and (c) V/CaSUP.

\subsection{Catalytic Activity}

Several research efforts on benzyl alcohol oxidation studies have revealed important factors affecting reaction activity such as type and catalyst loading, $\mathrm{H}_{2} \mathrm{O}_{2}$ : benzyl alcohol molar ratio, reaction duration and temperature [2,13,30-32]. To achieve optimum performance, these key effective factors were investigated in detail as follows.

\subsubsection{Metal Catalyst Effects}

The catalytic performance of the prepared catalysts, including the Pd/CaSUP and $\mathrm{V} / \mathrm{CaSUP}$ catalysts, were studied in the benzyl alcohol oxidation to benzaldehyde at $80{ }^{\circ} \mathrm{C}$ during $6 \mathrm{~h}$ of reaction and using $0.4 \mathrm{~g}$ of catalyst loading and a molar ratio of $\mathrm{H}_{2} \mathrm{O}_{2}$ to benzyl alcohol of 6:1. Table 1 shows the conversion and selectivity percentages of the catalysts, including the support (CaSUP) and the analysis without a catalyst. It is observable that the activity and selectivity of the V/CaSUP catalyst were lower than the Pd/CaSUP, which reported the conversion of benzyl alcohol and selectivity to benzaldehyde of $71 \%$ and $96 \%$, respectively. Therefore, catalysts based on noble metal nanoparticles such as Pd led to a superior activity to benzaldehyde than catalysts based on vanadium nanoparticles. The Pd/CaSUP was selected in the subsequent investigations for optimization of the reaction conditions. 
Table 1. Effect of the catalyst on benzyl alcohol oxidation.

\begin{tabular}{ccc}
\hline Catalyst & Conversion (\%) & Selectivity (\%) \\
\hline Without catalyst & 2 & 99 \\
CaSUP & 4 & 99 \\
Pd/CaSUP & 71 & 96 \\
V/CaSUP & 37 & 87 \\
\hline
\end{tabular}

Reaction conditions: $0.4 \mathrm{~g}$ catalyst, $80^{\circ} \mathrm{C}, 6 \mathrm{~h}, \mathrm{H}_{2} \mathrm{O}_{2} /$ benzyl alcohol $=6: 1$.

\subsubsection{Effect of the Catalyst Loading}

To investigate the effect of catalyst loading on benzyl alcohol oxidation, four different contents of the Pd/CaSUP catalyst were selected: 0.3, 0.4, 0.5 and $0.6 \mathrm{~g}$. Figure 6 displays the conversion and selectivity values of the catalyst.

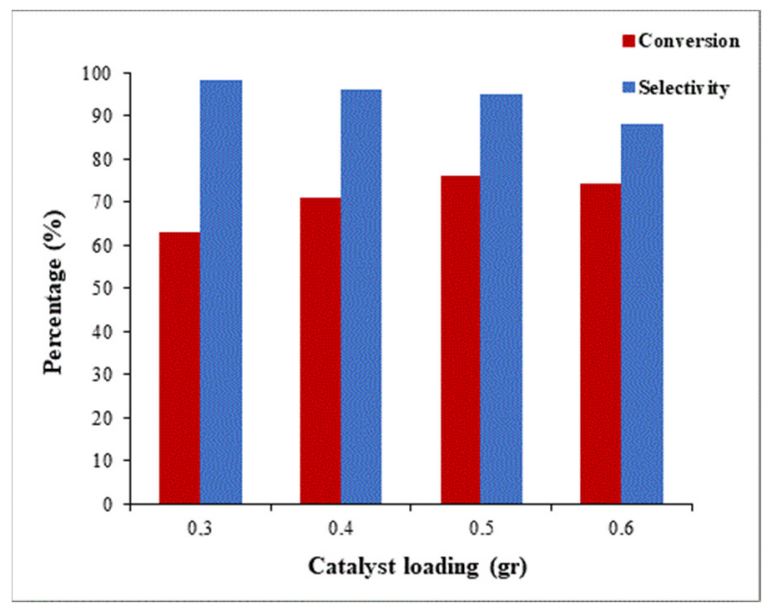

Figure 6. Effect of the catalyst loading in the benzyl alcohol oxidation reaction. Reaction conditions: $\mathrm{Pd} / \mathrm{CaSUP}, 80^{\circ} \mathrm{C}, 6 \mathrm{~h}, \mathrm{H}_{2} \mathrm{O}_{2}$ / benzyl alcohol = 6:1.

The increase in the amount of the Pd/CaSUP from $0.3 \mathrm{~g}$ to $0.6 \mathrm{~g}$ leads to an increase in conversion values from $63 \%$ to $74 \%$. These results are attributed to an increment of the active sites [2]. However, this continuous increase in the catalyst content has a negative effect on the selectivity of benzaldehyde. In this situation, the selectivity to benzaldehyde decreases from $99 \%$ to $89 \%$. The other by-product observed by GC-MS was benzoic acid. This indicates that an excess of catalysts could cause further oxidation of benzaldehyde. In order to find the best compromise between conversion and selectivity, $0.5 \mathrm{~g}$ catalyst loading was selected as the optimum content for the following studies.

\subsubsection{Effect of the Molar Ratio of $\mathrm{H}_{2} \mathrm{O}_{2}$ to Benzyl Alcohol}

In order to identify the optimum molar ratio of $\mathrm{H}_{2} \mathrm{O}_{2}$ to benzyl alcohol, molar ratios of 5:1, 6:1, 7:1 and 8:1 were investigated (Table 2). As shown, the conversion of benzyl alcohol obtained over the Pd/CaSUP increased with the amount of $\mathrm{H}_{2} \mathrm{O}_{2}$, which accelerates the reaction and shifts the reaction thermodynamics equilibrium to the right-hand side. At the same time, the selectivity to benzaldehyde decreased from $95 \%$ to $84 \%$. This can be attributed to the over-oxidation of benzyl alcohol to benzoic acid caused by the excess oxidant $\mathrm{H}_{2} \mathrm{O}_{2}$ [33]. In order to find the best compromise between conversion and selectivity, the molar ratio of 7:1 was selected as the optimum content for the following studies. 
Table 2. Effect of molar ratio of $\mathrm{H}_{2} \mathrm{O}_{2}$ to benzyl alcohol on the oxidation of benzyl alcohol.

\begin{tabular}{ccc}
\hline $\mathbf{H}_{\mathbf{2}} \mathbf{O}_{\mathbf{2}}$ : Benzyl Alcohol Molar Ratio & Conversion (\%) & Selectivity (\%) \\
\hline $5: 1$ & 69 & 95 \\
$6: 1$ & 76 & 95 \\
$7: 1$ & 80 & 93 \\
$8: 1$ & 83 & 84 \\
\hline
\end{tabular}

Reaction conditions: $\mathrm{Pd} / \mathrm{CaSUP}, 0.5 \mathrm{gr}, 80^{\circ} \mathrm{C}, 6 \mathrm{~h}$.

\subsubsection{Effect of the Temperature}

The strong dependence of the reaction temperature on benzyl alcohol oxidation is widely known. To investigate this effect, four different temperatures $\left(65,80,95\right.$ and $\left.110^{\circ} \mathrm{C}\right)$ were examined. It can be seen in Figure 7 that the catalytic activity greatly increased as the temperature rose from 65 to $80{ }^{\circ} \mathrm{C}$ with the conversion of benzyl alcohol from $67 \%$ to $80 \%$. Unceasingly increasing temperature has no significant effect on the conversion because of the decomposition of the $\mathrm{H}_{2} \mathrm{O}_{2}$. Moreover, the selectivity to benzaldehyde has the opposite trend in the conversion of benzyl alcohol. Thus, the optimum selected temperature was $80^{\circ} \mathrm{C}$.

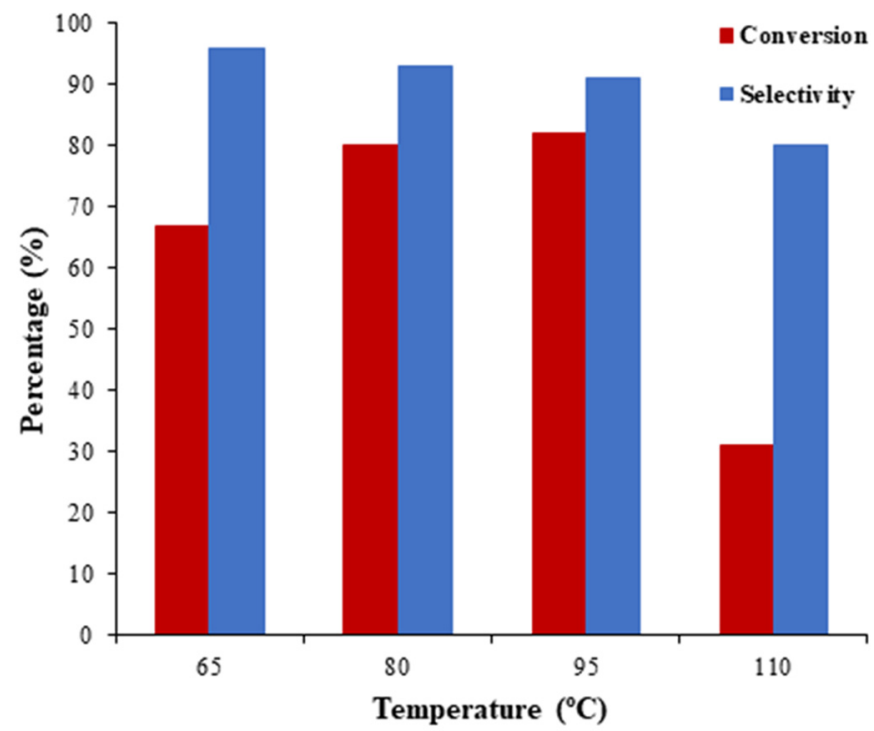

Figure 7. Effect of the reaction temperature in benzyl alcohol oxidation. Reaction conditions: $\mathrm{Pd} / \mathrm{CaSUP}, 0.5 \mathrm{gr}, 6 \mathrm{~h}, \mathrm{H}_{2} \mathrm{O}_{2}$ / Benzyl alcohol = 7:1.

\subsubsection{Effect of the Reaction Duration and Stability of the Catalyst}

Reaction duration is one of the most effective reaction factors, which play an important role in the oxidation of benzyl alcohol $[4,13,31,34]$. Table 3 shows the conversion and selectivity values of the reaction at 5, 6,7 and $8 \mathrm{~h}$. Prolonged reaction duration increases the conversion percentage from 74 to $89 \%$ but decreases the selectivity from 92 to $85 \%$, respectively. The excess reaction time inevitably leads to an increased possibility of interaction between benzaldehyde and $\mathrm{H}_{2} \mathrm{O}_{2}$, which is then oxidized to benzoic acid. These results show that the optimum reaction time is $7 \mathrm{~h}$.

Table 3. Effect of the reaction duration on the oxidation of benzyl alcohol.

\begin{tabular}{ccc}
\hline Time (h) & Conversion (\%) & Selectivity (\%) \\
\hline 5 & 74 & 92 \\
6 & 80 & 93 \\
7 & 88 & 89 \\
8 & 89 & 85 \\
\hline
\end{tabular}

Reaction conditions: $\mathrm{Pd} / \mathrm{CaSUP}, 0.5 \mathrm{gr}, 80^{\circ} \mathrm{C}, \mathrm{H}_{2} \mathrm{O}_{2}$ /benzyl alcohol = 7:1. 
The reusability of the Pd/CaSUP catalyst was carried out using the optimized conditions. At the end of the reaction, Pd/CaSUP was separated from the reaction mixture by centrifugation, thoroughly washed with an ethanol solution and dried. Then, it was reused for the next runs. Figure 8 shows the conversion percentage of the reaction during five runs. It was observed that the catalyst could be reused for at least five cycles without a significant loss of catalytic activity in the oxidation reaction of the benzyl alcohol. Additionally, the presence of palladium in the reaction mixture was analyzed by AAS, and no Pd content was detected in the solution.

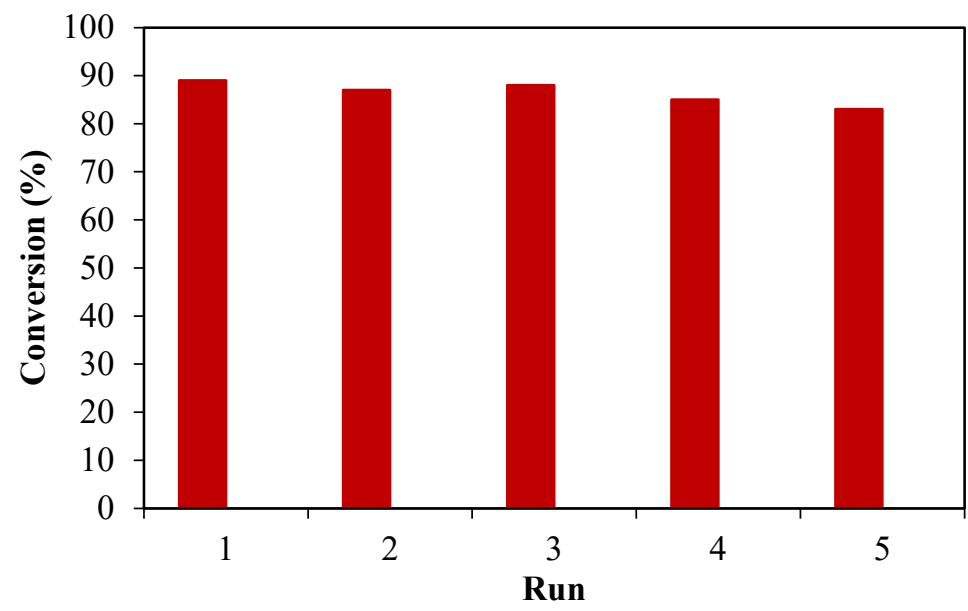

Figure 8. Recycling of Pd/CaSUP catalyst. Reaction conditions: Pd/CaSUP, 0.5 gr, $80{ }^{\circ} \mathrm{C}, 7 \mathrm{~h}$, $\mathrm{H}_{2} \mathrm{O}_{2}$ /benzyl alcohol = 7:1.

Table 4 summarizes the catalytic activity of the benzyl alcohol oxidation of some reported catalysts in the literature using $\mathrm{H}_{2} \mathrm{O}_{2}$ as an oxidant agent. Reasonable prices together with high catalytic activity are two important factors in the industrialization of the catalyst. This analysis shows that the Pd/CaSUP is one of the most effective and selective catalysts for the oxidation of benzyl alcohol to benzaldehyde below $100{ }^{\circ} \mathrm{C}$. The high yield of benzaldehyde can be related to the structural and basic properties of the nanoparticles of Pd supported by the CaSUP. In the first step of the reaction, the hydrophilicity of the $\mathrm{Ca}(\mathrm{OH})_{2}$ support can help to speed up the diffusion rate of the reactants. Secondly, the basic properties of the CaSUP mitigate the side reactions, such as the disproportionation reaction, that has been identified as the source of toluene formation in the solvent-free oxidation of benzyl alcohol. On the other hand, it can increase the yield of the benzaldehyde by facilitating the scission of the $\mathrm{O}-\mathrm{H}$ bond to produce an alkoxy intermediate via the hydrogen bond interaction with the surface of the support. Afterward, the alkoxy intermediate can dehydrogenate to form benzaldehyde [15]. Consequently, the CaSUP, derived from marine industry waste, has proven to be an effective low-cost support for the selective reaction of benzyl alcohol to benzaldehyde and can be potential support in other alcohol oxidation reactions to their respective aldehydes. 
Table 4. Comparison with other catalytic benzyl alcohol oxidation reactions.

\begin{tabular}{|c|c|c|c|c|c|}
\hline Catalyst & $\begin{array}{l}\text { Reaction } \\
\text { Condition }\end{array}$ & Conversion & Selectivity & Yield & Ref. \\
\hline Pdcatalysts supported on magnetic SBA-15 & $95^{\circ} \mathrm{C}, 3.5 \mathrm{~h}$ & $50 \%$ & $95 \%$ & - & [35] \\
\hline $\mathrm{Pd} /$ reduced graphene oxide aerogel & $140^{\circ} \mathrm{C}, 3 \mathrm{~h}$ & $\sim 80 \%$ & poor & - & [34] \\
\hline Oxidized Palladium Supported on Ceria Nanorods & $78{ }^{\circ} \mathrm{C}, 5 \mathrm{~h}$ & $\sim 93 \%$ & $96 \%$ & - & [36] \\
\hline $\begin{array}{c}\text { Doping carbon networks with phosphorus for } \\
\text { supporting Pd }\end{array}$ & $70^{\circ} \mathrm{C}, 10 \mathrm{~h}$ & $96.6 \%$ & $82.4 \%$ & - & [37] \\
\hline $\mathrm{Pd} / \mathrm{CeO}_{2}$-nitrogen doped graphene composite & $160^{\circ} \mathrm{C}, 6 \mathrm{~h}$ & $44.5 \%$ & $99.6 \%$ & - & [17] \\
\hline Pd nanoparticles loaded magnetic SBA-15 & $85^{\circ} \mathrm{C}, 6 \mathrm{~h}$ & & $83.2 \%$ & $71 \%$ & [16] \\
\hline Magnetic Core-Shell Nanostructured Palladium & & & & & \\
\hline $\begin{array}{c}\text { Catalysts } \\
\mathrm{Pd} / \mathrm{Fe}_{3} \mathrm{O}_{4} @ \mathrm{CeO}_{2}\end{array}$ & $100^{\circ} \mathrm{C}, 7 \mathrm{~h}$ & $80.5 \%$ & $94.8 \%$ & - & [38] \\
\hline $\begin{array}{c}\text { nitrogen-doped ordered mesoporous carbon } \\
\text { anchored Pd }\end{array}$ & $160^{\circ} \mathrm{C}, 3 \mathrm{~h}$ & $24.63 \%$ & $85.71 \%$ & - & [39] \\
\hline $\mathrm{Pd} / \mathrm{CaSUP}$ & $80^{\circ} \mathrm{C}, 7 \mathrm{~h}$ & 88 & 89 & & $\begin{array}{l}\text { This } \\
\text { work }\end{array}$ \\
\hline
\end{tabular}

\section{Materials and Methods}

\subsection{Materials}

All of the reagents were purchased from Merck chemical company.

\subsection{Catalyst Preparation}

In this work, the clamshell waste was used as a precursor to prepare a calciumcontaining support. To remove some impurities on the surface of clamshells, they were washed with hot water several times and then dried in the oven at $100{ }^{\circ} \mathrm{C}$. The dried clamshell was finely ground in a ball mill and then calcinated at $900{ }^{\circ} \mathrm{C}$ for $2 \mathrm{~h}$ at a heating ramp of $4{ }^{\circ} \mathrm{C} \cdot \mathrm{min}^{-1}$. The calcined support was labeled as CaSUP.

Monometallic $(\mathrm{Pd}, \mathrm{V})$ catalysts with metal loading of $1 \mathrm{wt} . \%$ on the CaSUP were prepared via wet impregnation method. For preparing the Pd catalyst, $2 \mathrm{~g}$ of the CaSUP support was added to $25 \mathrm{cc}$ of distilled water. The solution was stirred vigorously for $15 \mathrm{~min}$, followed by ultrasonic dispersion for $20 \mathrm{~min}$. Subsequently, a solution of an appropriate amount of $\mathrm{Pd}(\mathrm{OAC})_{2}$ in acetone was added dropwise to the aqueous CaSUP mixture. The resulting solution was dried at $40{ }^{\circ} \mathrm{C}$ and then calcinated at $400{ }^{\circ} \mathrm{C}$ for $4 \mathrm{~h}$ at a heating rate of $4{ }^{\circ} \mathrm{C} \cdot \mathrm{min}^{-1}$. The catalyst obtained was labeled as Pd/CaSUP. The V/CaSUP catalyst was prepared with the same procedure by using the $\mathrm{NH}_{4} \mathrm{VO}_{3}$ as a vanadium precursor.

\subsection{Characterization of Catalysts}

X-ray diffraction patterns were carried out in a GE X-ray diffractometer using CO $\mathrm{K} \alpha$ radiation and a $2 \theta$ scanning rate of $2^{\circ} \mathrm{min}^{-1}$. The infrared spectra were recorded on a Perkin-Elmer 1760X FTIR spectrometer with the sample dispersed in $\mathrm{KBr}$ pellets. Inductively Coupled Plasma (ICP) (Perkin-Elmer NexION 300XX) was used to analyze the $\mathrm{Pd}$ and V loading. Field-e mission scanning Electron Microscopy (FE-SEM) was utilized to provide topographical and elemental information of the catalysts. Specific surface area measurements were carried out using Brunauer-Emmet-Teller isotherms (BET method) in a Micrometrics Belsorp instrument. Transmission electron microscopy (TEM) images were obtained from a CM-120 Philips machine. The reaction products were analyzed using gas chromatography-mass spectroscopy (GC-MS) (Agilent, model Mass 5973N with an MP- 5 column from Agilent, $30 \mathrm{~m} \times 0.25 \mathrm{~mm}, 0.25 \mu \mathrm{m}$ ) equipped with a flame ionization detector (FID). Atomic absorption spectrophotometry (AAS) was obtained from GBC 932 plus equipment. 


\subsection{Catalytic Reaction}

The liquid-phase benzyl alcohol oxidation with $\mathrm{H}_{2} \mathrm{O}_{2}$ as an oxidant was performed in a $50 \mathrm{~cm}^{3}$ three-necked flask equipped with a condenser. The appropriate amount of catalyst was added to the flask containing $28 \mathrm{mmol}$ of benzyl alcohol. Then, the system was transferred into an oil bath (at constant heating). At the desired temperature, $\mathrm{H}_{2} \mathrm{O}_{2}(30 \%$ solution) was injected into the mixture using a syringe, and the contents were continuously stirred for $8 \mathrm{~h}$. At the end of the reaction, the mixture was centrifuged to separate the catalyst. GC-MS analysis was used to confirm the chemical composition of the products.

\section{Conclusions}

This study describes a low-cost and effective method of obtaining active catalysts from waste clamshell to obtain benzaldehyde in the solvent-free oxidation of benzyl alcohol. We have demonstrated that $\mathrm{Pd}$ nanoparticles supported on clamshell-derived supports are efficient for the selective oxidation of benzyl alcohol using $30 \%$ aqueous $\mathrm{H}_{2} \mathrm{O}_{2}$, exhibiting excellent catalytic conversion (88\%) and selectivity $(89 \%)$ under solvent-free and optimized tested conditions. These results provide important insights into the benzyl alcohol oxidation process for industrial applications.

Author Contributions: N.S.S.: investigation, writing—original draft preparation; B.A.: conceptualization, supervision, funding acquisition, writing — review and editing; M.J.: methodology, investigation; A.K.: software, investigation; M.V.M.-H.: funding acquisition, supervision. All authors have read and agreed to the published version of the manuscript.

Funding: This research was funded by the Materials and Energy Research Center (MERC), Grant No. 771394075, and the Spanish National Research Council (CSIC) through project COOPB20558.

Conflicts of Interest: The authors declare no conflict of interest.

\section{References}

1. Zhao, G.; Deng, M.; Jiang, Y.; Hu, H.; Huang, J.; Lu, Y. Microstructured Au/Ni-fiber catalyst: Galvanic reaction preparation and catalytic performance for low-temperature gas-phase alcohol oxidation. J. Catal. 2013, 301, 46-53. [CrossRef]

2. Cang, R.; Lu, B.; Li, X.; Niu, R.; Zhao, J.; Cai, Q. Iron-chloride ionic liquid immobilized on SBA-15 for solvent-free oxidation of benzyl alcohol to benzaldehyde with $\mathrm{H}_{2} \mathrm{O}_{2}$. Chem. Eng. Sci. 2015, 137, 268-275. [CrossRef]

3. Galvanin, F.; Sankar, M.; Cattaneo, S.; Bethell, D.; Dua, V.; Hutchings, G.J.; Gavriilidis, A. On the development of kinetic models for solvent-free benzyl alcohol oxidation over a gold-palladium catalyst. Chem. Eng. J. 2018, 342, 196-210. [CrossRef]

4. Lukato, S.; Wendt, O.F.; Wallenberg, R.; Kasozi, G.N.; Naziriwo, B.; Persson, A.; Folkers, L.C.; Tebandeke, E. Selective oxidation of benzyl alcohols with molecular oxygen as the oxidant using Ag-Cu catalysts supported on polyoxometalates. Results Chem. 2021, 3, 100150. [CrossRef]

5. $\quad$ Fei, J.; Sun, L.; Zhou, C.; Ling, H.; Yan, F.; Zhong, X.; Lu, Y.; Shi, J.; Huang, J.; Liu, Z. Tuning the Synthesis of Manganese Oxides Nanoparticles for Efficient Oxidation of Benzyl Alcohol. Nanoscale Res. Lett. 2017, 12, 23. [CrossRef]

6. Deori, K.; Kalita, C.; Deka, S. (100) surface-exposed $\mathrm{CeO}_{2}$ nanocubes as an efficient heterogeneous catalyst in the tandem oxidation of benzyl alcohol, para-chlorobenzyl alcohol and toluene to the corresponding aldehydes selectively. J. Mater. Chem. A 2015, 3, 6909-6920. [CrossRef]

7. Choudhary, V.R.; Dumbre, D.K. Supported nano-gold catalysts for epoxidation of styrene and oxidation of benzyl alcohol to benzaldehyde. Top. Catal. 2009, 52, 1677-1687. [CrossRef]

8. Bijudas, K.; Bashpa, P.; Bibin, V.P.; Nair, L.; Priya, A.P.; Aswathy, M.; Krishnendu, C.; Lisha, P. Selective synthesis of benzaldehydes by hypochlorite oxidation of benzyl alcohols under phase transfer catalysis. Bull. Chem. React. Eng. Catal. 2015, 10, 38-42. [CrossRef]

9. Göksu, H.; Burhan, H.; Mustafov, S.D.; Şen, F. Oxidation of Benzyl Alcohol Compounds in the Presence of Carbon Hybrid Supported Platinum Nanoparticles (Pt@CHs) in Oxygen Atmosphere. Sci. Rep. 2020, 10, 5439. [CrossRef]

10. Li, X.; Cao, R.; Lin, Q. Selective oxidation of alcohols with $\mathrm{H}_{2} \mathrm{O}_{2}$ catalyzed by long chain multi-SO3H functionalized heteropolyanion-based ionic liquids under solvent-free conditions. Catal. Commun. 2015, 69, 5-10. [CrossRef]

11. Gaspar, F.; Nunes, C.D. Selective catalytic oxidation of benzyl alcohol by $\mathrm{MooO}_{2}$ nanoparticles. Catalysts 2020, 10, 265. [CrossRef]

12. Bourbiaux, D.; Mangematin, S.; Djakovitch, L.; Rataboul, F. Selective Aerobic Oxidation of Benzyl Alcohols with Palladium(0) Nanoparticles Suspension in Water. Catal. Lett. 2021, 151, 3239-3249. [CrossRef]

13. Crombie, C.M.; Lewis, R.J.; Taylor, R.L.; Morgan, D.J.; Davies, T.E.; Folli, A.; Murphy, D.M.; Edwards, J.K.; Qi, J.; Jiang, H.; et al. Enhanced Selective Oxidation of Benzyl Alcohol via in Situ $\mathrm{H}_{2} \mathrm{O}_{2}$ Production over Supported Pd-Based Catalysts. ACS Catal. 2021, 11, 2701-2714. [CrossRef] 
14. Neves, P.; Valente, A.A.; Lin, Z. Mild Liquid Phase Oxidation of Benzyl Alcohol in the Presence of Microporous Framework Copper Silicates. Eur. J. Inorg. Chem. 2020, 2020, 1172-1176. [CrossRef]

15. Chan-Thaw, C.E.; Savara, A.; Villa, A. Selective benzyl alcohol oxidation over pd catalysts. Catalysts 2018, 8, 431. [CrossRef]

16. Li, Y.; Huang, J.; Hu, X.; Lam, F.L.Y.; Wang, W.; Luque, R. Heterogeneous Pd catalyst for mild solvent-free oxidation of benzyl alcohol. J. Mol. Catal. A Chem. 2016, 425, 61-67. [CrossRef]

17. Hu, Z.; Zhou, G.; Xu, L.; Yang, J.; Zhang, B.; Xiang, X. Preparation of ternary Pd/CeO 2 -nitroben doped graphene composites as recyclable catalysts for solvent-free aerobic oxidation of benzyl alcohol. Appl. Surf. Sci. 2019, 471, 852-861. [CrossRef]

18. Zhao, Y.; Li, C.H.; Yu, Z.X.; Yao, K.F.; Ji, S.F.; Liang, J. Effect of microstructures of Pt catalysts supported on carbon nanotubes (CNTs) and activated carbon (AC) for nitrobenzene hydrogenation. Mater. Chem. Phys. 2007, 103, 225-229. [CrossRef]

19. Cánepa, A.L.; Elías, V.R.; Vaschetti, V.M.; Sabre, E.V.; Eimer, G.A.; Casuscelli, S.G. Selective oxidation of benzyl alcohol through eco-friendly processes using mesoporous V-MCM-41, Fe-MCM-41 and Co-MCM-41 materials. Appl. Catal. A Gen. 2017, 545, 72-78. [CrossRef]

20. Ji, W.Y.; Sung, H.J.; Chang, J.S. Vapor-phase oxidation of alkylaromatics over V/ $\mathrm{TiO}_{2}$ and VSb/ $\mathrm{Al}_{2} \mathrm{O}_{3}$ catalysts: Effect of alkali metals. Bull. Korean Chem. Soc. 2007, 28, 2405-2408. [CrossRef]

21. Wang, B.; Lin, M.; Ang, T.P.; Chang, J.; Yang, Y.; Borgna, A. Liquid phase aerobic oxidation of benzyl alcohol over Pd and Rh catalysts on N-doped mesoporous carbon: Effect of the surface acido-basicity. Catal. Commun. 2012, 25, 96-101. [CrossRef]

22. Verziu, M.; Coman, S.M.; Richards, R.; Parvulescu, V.I. Transesterification of vegetable oils over CaO catalysts. Catal. Today 2011, 167, 64-70. [CrossRef]

23. Aghabarari, B.; Martinez-Huerta, M.V. Biodiesel Production Using Calcined Waste Filter Press Cake from a Sugar Manufacturing Facility as a Highly Economic Catalyst. JAOCS, J. Am. Oil Chem. Soc. 2016, 93, 773-779. [CrossRef]

24. Asikin-Mijan, N.; Taufiq-Yap, Y.H.; Lee, H.V. Synthesis of clamshell derived $\mathrm{Ca}(\mathrm{OH})_{2}$ nano-particles via simple surfactanthydration treatment. Chem. Eng. J. 2015, 262, 1043-1051. [CrossRef]

25. Islam, K.N.; Bakar, M.Z.B.A.; Ali, M.E.; Hussein, M.Z.B.; Noordin, M.M.; Loqman, M.Y.; Miah, G.; Wahid, H.; Hashim, U. A novel method for the synthesis of calcium carbonate (aragonite) nanoparticles from cockle shells. Powder Technol. 2013, 235, 70-75. [CrossRef]

26. Wan, Z.; Hassan, H. Heterogeneous catalyst acid-activated clamshell for fenton-like oxidation of reactive black 5 solutions. In Proceedings of the 2012 IEEE Symposium on Humanities, Science and Engineering Research, Kuala Lumpur, Malaysia, 24-27 June 2012; pp. 277-281.

27. Engin, B.; Demirtaş, H.; Eken, M. Temperature effects on egg shells investigated by XRD, IR and ESR techniques. Radiat. Phys. Chem. 2006, 75, 268-277. [CrossRef]

28. Suprapto, S.; Fauziah, T.R.; Sangi, M.S.; Oetami, T.P.; Qoniah, I.; Prasetyoko, D. Calcium oxide from limestone as solid base catalyst in transesterification of Reutealis trisperma oil. Indones. J. Chem. 2016, 16, 208-213. [CrossRef]

29. Yao, Z.; Xia, M.; Ge, L.; Chen, T.; Li, H.; Ye, Y.; Zheng, H. Mechanical and thermal properties of polypropylene (PP) composites filled with $\mathrm{CaCO} 3$ and shell waste derived bio-fillers. Fibers Polym. 2014, 15, 1278-1287. [CrossRef]

30. Noshiranzadeh, N.; Mayeli, M.; Bikas, R.; Ślepokura, K.; Lis, T. Selective catalytic oxidation of benzyl alcohol to benzaldehyde by a mononuclear oxovanadium $(\mathrm{V})$ complex of a bis(phenolate) ligand containing bulky tert-butyl substituents. Transit. Met. Chem. 2014, 39, 33-39. [CrossRef]

31. Choudhary, V.R.; Dumbre, D.K. Solvent-free selective oxidation of benzyl alcohol to benzaldehyde by tert-butyl hydroperoxide over U3O8-supported nano-gold catalysts. Appl. Catal. A Gen. 2010, 375, 252-257. [CrossRef]

32. Zhan, G.; Hong, Y.; Mbah, V.T.; Huang, J.; Ibrahim, A.R.; Du, M.; Li, Q. Bimetallic Au-Pd/MgO as efficient catalysts for aerobic oxidation of benzyl alcohol: A green bio-reducing preparation method. Appl. Catal. A Gen. 2012, 439-440, 179-186. [CrossRef]

33. Adam, F.; Ooi, W.T. Selective oxidation of benzyl alcohol to benzaldehyde over Co-metalloporphyrin supported on silica nanoparticles. Appl. Catal. A Gen. 2012, 445-446, 252-260. [CrossRef]

34. Wang, X.L.; Wu, G.D.; Zhai, Z.L.; Dai, Y.W. Solvent-Free Oxidation of Benzyl Alcohol by $30 \% \mathrm{H}_{2} \mathrm{O}_{2}$ over LDH Hosted Chromium Complex. Adv. Mater. Res. 2014, 1015, 497-500. [CrossRef]

35. Li, Y.; Sabbaghi, A.; Huang, J.; Li, K.C.; Tsui, L.S.; Lam, F.L.Y.; Hu, X. Aerobic oxidation of benzyl alcohol: Influence from catalysts basicity, acidity, and preparation methods. Mol. Catal. 2020, 485, 110789. [CrossRef]

36. Moeini, S.S.; Battocchio, C.; Casciardi, S.; Luisetto, I.; Lupattelli, P.; Tofani, D.; Tuti, S. Oxidized palladium supported on ceria nanorods for catalytic aerobic oxidation of Benzyl alcohol to benzaldehyde in protic solvents. Catalysts 2019, 9, 847. [CrossRef]

37. Guo, W.; Niu, S.; Ji, X.; Yu, W.; Lin, T.W.; Wu, Y.; Li, Y.; Shao, L. Doping carbon networks with phosphorus for supporting Pd in catalyzing selective oxidation of benzyl alcohol. J. Nanoparticle Res. 2018, 20, 180. [CrossRef]

38. Kong, L.; Wang, C.; Gong, F.; Zhu, W.; Zhong, Y.; Ye, X.; Li, F. Magnetic Core-Shell Nanostructured Palladium Catalysts for Green Oxidation of Benzyl Alcohol. Catal. Lett. 2016, 146, 1321-1330. [CrossRef]

39. Song, H.; Liu, Z.; Gai, H.; Wang, Y.; Qiao, L.; Zhong, C.; Yin, X.; Xiao, M. Nitrogen-dopped ordered mesoporous carbon anchored $\mathrm{Pd}$ nanoparticles for solvent free selective oxidation of benzyl alcohol to benzaldehyde by using $\mathrm{O}_{2}$. Front. Chem. 2019, 7, 458. [CrossRef] 